\title{
The Influence of Khat Market on Attainment of Primary Education in Mogadishu, Somalia
}

\author{
Bashir Ahmed Abshir \\ Candidate master at University of Nairobi, Kenya.
}

\begin{abstract}
The purpose of this paper is to investigate the influence of khat market on attainment of primary education in Mogadishu, Somalia. The study adopted the descriptive survey research design whose purpose is to describe the state of affairs and involves a method of collecting data by interviewing or administering questionnaires to a sample of individuals. The results of the questionnaire were then analyzed with the aid of SPSS. A sample size of 66 respondents of a targeted population of 220 was selected. The study found that there is a negative relationship between khat market and attainment of primary education.From the finding the study recommends that the Ministry of Education, Culture and Higher Education in conjunction with the Ministry of Woman and Human Rights Development should recognize and enforce the right of the child to be protected from economic exploitation at the family level and from performing any work that is likely to be hazardous or to interfere with the child's education. And also the study recommended that the Ministry of Education, Culture and Higher Education in conjunction with the school heads should provide special remedial and weekend programmes for school going children. These programmes should incorporate discussions on the impact of khat market on education.
\end{abstract}

Keywords: khat market, selling of khat, awareness level, peer influence, attainment of primary education.

DOI: $10.7176 / \mathrm{JEP} / 11-12-13$

Publication date: April $30^{\text {th }} 2020$

\section{Introduction}

Khat (Catha edulis) also known as Abyssinian tea, Africa salad, Bushman 's tea, Gat, Kat, Miraa, Tohai and Chat is a flowering shrub, native to the region extending from Eastern to South Africa, as well the Arabian Peninsula (Sikiru et al., 1999). According to Fitzgerald (2009), Khat originated in Ethiopia and later spread to Somalia, Kenya, Uganda, Tanzania, the Congo, Zambia, Zimbabwe, Afghanistan, Yemen and Madagascar. According to a famous legend in Ethiopia the first human to use Khat was a Yemen herder who noticed the effect of the leaves of the plant on his goats and tried them himself after which he experienced wakefulness and added strength (Getahum et al., 1923).

Globally, it is estimated that 10 million people consume Khat (NIDA, 2010). (Hassan et al., 2007) noted that the uptake of licit and illicit drugs by the youth is a major problem globally. Research conducted on the topic of drug abuse by youth in different areas reveal a significant level of delinquency (Ndetei et al., 1997). This triggers the need to comprehend the effect of khat intake on the health of the primary school pupils and then devise intervention strategies geared towards abuse control.

Khat originated in East Africa and the Arabian Penisula. From here khat has spread to various parts of the world. Since the thirteenth century khat has been used as a recreational drug. Khat is legal in many countries except the United States among others. The World Health Organization (WHO) declared khat a drug in 1980. World Health Organization (2003) defines abuse of drug as the intake of any drug in a different way from the prescribed medical or social arrays within a cultural setup WHO (2003). Fitzgerald (2009) observes that khat initially came from Ethiopia then spread to other countries including Kenya, Somalia, Uganda, Congo, Zimbabwe, Tanzania, Zambia, Madagascar, Afghanistan and Yemen. With an estimated 20 million users in the Horn of Africa alone, and a growing and lucrative business produced by the 500,000 farmers across the Horn of Africa and Arabian Peninsula, Khat is a multimillion business for producers from Kenya and Ethiopia and a heavy economic burden to Somalia, the biggest consumer in the region. More than 15 cargo flights of Khat arrive in Somalia's capital, Mogadishu, daily from Kenya, bringing in about 12,000 bags of the stimulant with a total value of $\$ 400,000$. Many Somali scholars have argued that if Somalia did not import khat, the country would be one of the most socially and economically developed countries in Africa.

In Somalia, Khat-chewing became a widespread problem in the mid1960s. Before 1960, Khat was grown on a limited scale and was chewed only in the northern areas of the country. The problem was initially limited to a small number of people (Elmi A., 1983). Within past two decades the consumption of Khat has increased dramatically. Before 1980s Khat was mostly chewed on Thursdays and Fridays, in connection with particular rituals such as weddings, funerals, religious gatherings or readings (e.g. Maulids), and occasions when it was essential to stay awake such as during truck driving or preparing for exams (Hansen,, 2010).Currently, khat is chewed worldwide and Somalia is one of the countries with the highest proportion of khat users. The practice of chewing khat ("jaad" or "qaad") started at different times in the different parts of Somalia. Notably, $80 \%$ of khat users are estimated to be less under35 years of age (Nabuzoka and Badhadhe, 2000). 


\section{Statement of the problem}

Khat market has been increasing time after time. Khat is a vital trade in Somalia and has been increasing exponentially costing millions of dollars annually. In 2012, Transitional Federal Government, Puntland and Somaliland spent more than USD 300 million of foreign exchange (Kafi \& Mberia, 2016). Khat has a negative and dangerous effect on school child, families, and the whole of the society. The use of khat; a substance that most Somalis perceive as a leisurely substance, has been associated with the social problems suffered by Somalis in Mogadishu. Using children as a cheap source of labour in khat market is likely to have far and wide reaching effects on the pupils' concentration in school. In Banadir Region, there are high poverty levels; approximately $70 \%$ of the households live below the poverty line despite the increase in khat markets in the region. Somalia has one of the world's lowest gross enrolment rates for primary school-aged children with only 30 percent children at primary education (Somalia Education Cluster, 2017).

According to a study by Nabuzoka and Badhadhe 2000, there is proof that the khat-chewing habit has changed quantitatively in the twenty first century such that what was previously a formalized and strongly regulated social habit presently has features of extremeness, casualness and lack of normal control. Consequently, several studies have been done on khat and its effects on almost all aspects of the lives of the inhabitants in these areas.

The negative effects of khat have been discussed globally (Patel, 2005, Hassan, 2007, Fitzgerald, 2009) but its effects on attainment of primary education has not been extensively done in Somalia. The use of khat results to substantial deleterious physiological, psychological and sociological impact on neurotic users (Patel, 2000; Odenwald, 2007). Peer influence is hereby most likely to be an influencing factor. A misconception that Khat can enhance performance in exams exists as part of the informal education that is misleading to the youth. Culture seems to bare much influence on the individual behavior (Ngeranwa, 2013).

In Banadir Region, khat trade is the one of the largest source of income for the Mogadishu people and much effort has been put on studying its effects on health but few or no studies have been done concerning effects of on attainment of primary education. However, it is manifest from diverse studies that, the psychosocial and medical effects of khat chewing are not only harmful to the individual but also to the community at large (Babu and Sikiru, 2009). Therefore, this study therefore sought to establish the influence of khat market on attainment of primary education in Mogadishu, Somalia. The paper has the following objectives:

- To determine the effect of khat selling on attainment of primary school education in Mogadishu, Somalia.

- To investigate the effects of awareness level on attainment of primary education in Mogadishu, Somalia.

- To establish the extent to which peer influence in khat market influence on attainment of primary school education in Mogadishu, Somalia.

\section{LITERATURE REVIEW}

\subsection{Selling of Khat and attainment of primary education}

But as the community obtain money from khat, and extensively chew it, they lack the motivation to reinvest in other developmental projects that are income generating hence they remain poor. There is a strong relationship between child-labour and low school retention rate. School dropout is an alarming issue worldwide. Bridgelang (2006) and ILO (2007) revealed that child-labour is one of the main causes of school dropout.

\subsection{Awareness level and attainment of primary education}

In many African cultures, the idea that children's work in the household is part of a normal socialization process, which prepares them for their future roles in life is a common perception. A study by Mureithi (2008) showed that child wage labour was found mostly on commercial agricultural plantations where children were estimated to account for 20 to 30 per cent of the casual labour force. A portion of child labourers tend to drop out of school because their parents think that education is immaterial. In a study by UNICEF (1999) on child labour in Nepal, it is noted that parents' awareness of the harmful effects of child labour has been increased through Parenting Education Initiative.

\subsection{Peer influence and attainment of primary education}

Hopkins (1983) acknowledged that drug use among peers played the strongest part in adolescent drug use. Conger \& Peterson (1984) reported that in a national survey conducted in 1981 in the United States, most youngsters said that they used drugs due to peer pressure especially those aged between 13 to 18 years. Karechio (1994) also agrees that a young person will be encouraged by his friends to take drug when the rest of the group is doing so. A study done in Ethiopia's Jimma University College on the prevalence of khat showed that chewers were adolescents belonging to the age group of 21-25 years implying that when they are free from family supervision they are susceptible to be easily hooked with drugs (Gorfu, 2010). 


\section{METHODOLOGY}

\subsection{Research Design and Target Population}

The study used a descriptive research design to achieve the study objectives. The Office of Human Research Protection (2013) defines a descriptive study as a study that is conducted with the aim of establishing the relationship between variables without affecting the environment.

The study involved five private primary schools targeting the standard 7 and 8 classes which have an enrolment of 220 pupils making up the population of this study. Simple random sampling method was used to select a sample of 66 pupils. The proportion of the sample was $30 \%$ of the population of 220 standard 7 and 8 pupils. Mugenda and Mugenda (2003) recommend 30\% of the population as a good sample.

\subsection{Sample Procedure}

The primary data of this study collected by using questionnaire, Questionnaire is used in view of the realty that the study will concerned with variables that can't be observing such information, The questionnaires of this study was developed by the researcher and they based on literature review whose congruent their dimensions of research and research objectives through steps in order to get relevant information on the research questions then researchers structured questionnaires into three sections: part (A) profile of the respondents, part (B) research questions one. Part (C) research questions two; and format of questionnaire designed as five point liker's scale.

\section{Reliability Test}

To measure reliability the researchers used Cronbach's alpha. It is most commonly used when there are multiple Likert questions in a survey questionnaire that form a scale, and you wish to determine if the scale is reliable. Reliability test was made and the result shows a chronbach's alpha of 0 . and this shows that it is reliable since there are some scholars who suggest that a chronbach's alpha of 0.71 is reliable, as it is argued by kathuri \& palls (1993) the instrument with validity coefficient of at least 0.70 or $70 \%$ are accepted as valid in research.

\section{FINDINGS}

\subsection{Profile of Respondents}

As shown in tables 4.1, the majority of the respondents, 37(56.1\%) were male compared with, 29(43.9\%) of female. Hence, the above finding reveals that majority of the respondents were male. In terms of age, $54(81.8 \%)$ of the respondents were between 15 - 20years old. In terms of class, $50 \%$ were in class 7 and $50 \%$ were in class 8 .

\begin{tabular}{|l|l|l|l|}
\hline Demographic Profile & Frequency & Percent & Cumulative \% \\
\hline Gender & 37 & 56.1 & 56.1 \\
\hline Male & 29 & 43.9 & 100 \\
\hline Female & 66 & 100 & \\
\hline Total & \multicolumn{5}{|l|}{} \\
\hline Age & 54 & 81.8 & 81.8 \\
\hline $15-20$ & 10 & 15.2 & 97 \\
\hline $20-30$ & 2 & 3 & 100 \\
\hline Above 30 & 66 & 100 & \\
\hline Total & \multicolumn{5}{|l|}{} \\
\hline Class & 33 & 50 & 50 \\
\hline Class 7 & 33 & 50 & 100 \\
\hline Class 8 & 66 & 100 & \\
\hline Total &
\end{tabular}

\section{Selling of Khat and attainment of primary education}

The study sought to establish whether khat affects attainment of primary education and the findings are presented in table 4.2. The findings indicate that $43.9 \%$ agreed that they spend more time transporting and selling khat than going to school, $53 \%$ agreed that Khat trading has negatively affected school enrollment, $31.8 \%$ agreed that they involved in selling khat and $40.9 \%$ agreed that Khat market is more beneficial than going to school. The overall aggregate mean score for this khat selling was 3.135 and the standard deviation at 1.281. Psacharopaulus (2009) showed that children who devout their time to such activities, instead of utilizing their time to study, do it at the expense of their studies and this eventually affects their educational performance. Children who are involved in child labour lose two years of schooling. 
Table 4.2 Khat Selling and attainment of primary education

\begin{tabular}{|l|l|l|l|l|l|l|l|}
\hline Khat selling and attendance of school & $\begin{array}{l}\text { SA } \\
(\mathbf{\%})\end{array}$ & $\begin{array}{l}\mathbf{A} \\
(\mathbf{\%})\end{array}$ & $\begin{array}{l}\mathbf{N} \\
(\mathbf{\%})\end{array}$ & $\begin{array}{l}\mathbf{D} \\
(\mathbf{\%})\end{array}$ & $\begin{array}{l}\text { SD } \\
(\%)\end{array}$ & Mean & $\begin{array}{l}\text { Std. } \\
\text { Deviation }\end{array}$ \\
\hline $\begin{array}{l}\text { I spend more time transporting and selling } \\
\text { khat than going to school }\end{array}$ & 15.2 & 43.9 & 6.1 & 24.2 & 10.6 & 3.29 & 1.286 \\
\hline $\begin{array}{l}\text { Khat trading has negatively affected school } \\
\text { enrollment }\end{array}$ & 6.1 & 53.0 & 7.6 & 19.7 & 13.6 & 3.18 & 1.227 \\
\hline Am involved in selling khat & 21.2 & 31.8 & 10.6 & 13.6 & 22.7 & 3.15 & 1.491 \\
\hline $\begin{array}{l}\text { Khat market is more beneficial than going to } \\
\text { school }\end{array}$ & 3.0 & 40.9 & 6.1 & 42.4 & 7.6 & 2.92 & 1.086 \\
\hline Average score & & \multicolumn{7}{|c|}{$\mathbf{3 . 1 3 5}$} & $\mathbf{1 . 2 8 1}$ \\
\hline
\end{tabular}

\section{Awareness Level and attainment of primary school education}

The study sought to find out how awareness level affects attainment of primary education and the findings presented in table 4.3. $40.9 \%$ of the respondents agreed that there is readily available information on the impact of khat on attainment of education, $34.8 \%$ agreed that teachers and parents organize discussions to enlighten me on the effects of khat and consumption, $48.5 \%$ agreed that education is more important than khat selling in helping reduce poverty, $28.8 \%$ agreed that khat consumption can affect a student's ability to succeed in school, $24.2 \%$ agreed that their friends prefer khat market to going to school, $42.4 \%$ agreed that the set rules and regulations give adequate guidance on the impact of khat and $37.9 \%$ agreed that their friends know the importance of education as opposed to khat selling. The overall aggregate mean score for this awareness level was 2.99and the standard deviation at 1.278. A study by Grootaert and Kanbur (1995) indicates that there is ample evidence that the education and employment status of the parents affect child labour decision. In a study by UNICEF (1999) on child labour in Nepal, it is noted that parents' awareness of the harmful effects of child labour has been increased through Parenting Education Initiative.

Table 4.3 Awareness level and attainment of primary school education

\begin{tabular}{|c|c|c|c|c|c|c|c|}
\hline Awareness level & $\begin{array}{l}\text { SA } \\
(\%)\end{array}$ & $\begin{array}{l}\text { A } \\
(\%)\end{array}$ & $\begin{array}{l}\mathrm{N} \\
(\%)\end{array}$ & $\begin{array}{l}\text { D } \\
(\%)\end{array}$ & $\begin{array}{l}\text { SD } \\
(\%)\end{array}$ & Mean & $\begin{array}{l}\text { Std. } \\
\text { Deviation }\end{array}$ \\
\hline $\begin{array}{l}\text { There is readily available information on the impact of } \\
\text { Khat market } \\
\text { on attainment of education }\end{array}$ & 19.7 & 40.9 & 3.0 & 25.8 & 10.6 & 3.33 & 1.340 \\
\hline $\begin{array}{l}\text { Teachers and parents organize discussions to enlighten } \\
\text { me on the effects of Khat market and consumption }\end{array}$ & 9.1 & 34.8 & 7.6 & 21.2 & 27.3 & 2.77 & 1.412 \\
\hline $\begin{array}{l}\text { Education is more important than khat selling in helping } \\
\text { reduce poverty }\end{array}$ & 12.1 & 48.5 & 18.2 & 19.7 & 1.5 & 3.50 & 0.996 \\
\hline $\begin{array}{l}\text { Khat consumption can affect a student's ability to } \\
\text { succeed in school }\end{array}$ & 13.6 & 28.8 & 9.1 & 31.8 & 16.7 & 2.91 & 1.356 \\
\hline My friends prefer khat market to going to school & 7.6 & 24.2 & 1.5 & 39.4 & 27.3 & 2.45 & 1.326 \\
\hline $\begin{array}{l}\text { The set rules and regulations give adequate guidance } \\
\text { on the impact }\end{array}$ & 3.0 & 42.4 & 6.1 & 30.3 & 18.2 & 2.82 & 1.252 \\
\hline $\begin{array}{l}\text { My friends know the importance of education as } \\
\text { opposed to khat selling }\end{array}$ & 12.1 & 37.9 & 10.6 & 31.8 & 7.6 & 3.15 & 1.218 \\
\hline Average score & \multicolumn{7}{|c|}{$2.99 \quad 1.278$} \\
\hline
\end{tabular}

\section{Peer influence and attainment of primary education}

The study sought to find out how peer influence affects attainment of primary education and the findings presented in table 4.4. From the findings $53.0 \%$ agreed that learners are easily influenced by their peers to join khat trade, $25.8 \%$ agreed that learners sneak out of school in groups to go khat market, $60.6 \%$ agreed that boys drop out of school to chew khat. The overall aggregate mean score for this peer influence was 3.47 and the standard deviation at 1.217 . 
Table 4.4 Peer influence and attainment of primary education

\begin{tabular}{|l|l|l|l|l|l|l|l|}
\hline Peer influence & $\begin{array}{l}\text { SA } \\
(\%)\end{array}$ & $\begin{array}{l}\mathbf{A} \\
(\%)\end{array}$ & $\begin{array}{l}\mathbf{N} \\
(\%)\end{array}$ & $\begin{array}{l}\text { D } \\
(\%)\end{array}$ & $\begin{array}{l}\text { SD } \\
(\%)\end{array}$ & Mean & $\begin{array}{l}\text { Std. } \\
\text { Deviation }\end{array}$ \\
\hline $\begin{array}{l}\text { Learners are easily influenced by their } \\
\text { peers to join khat trade }\end{array}$ & 25.8 & 53.0 & 4.5 & 6.1 & 10.6 & 3.77 & 1.213 \\
\hline $\begin{array}{l}\text { Learners sneak out of school in groups to } \\
\text { go khat market }\end{array}$ & 19.7 & 25.8 & 22.7 & 13.6 & 18.2 & 3.15 & 1.384 \\
\hline Boys drop out of school to chew khat & 7.6 & 60.6 & 9.1 & 18.2 & 4.5 & 3.48 & 1.026 \\
\hline Average score
\end{tabular}

\section{Attainment of education}

The study sought to establish the effects on attainment of primary education. Table 4.5 presents the findings from the respondents $34.8 \%$ agreed that they value khat as opposed to getting an education, 31.8\% agreed that Khat effects on their performance in school, $75.8 \%$ agreed that Khat has led to school drop outs and $80.3 \%$ agreed that participating in selling of khat affects the attainment of education. The overall aggregate mean score for this attainment of education was 3.22 and the standard deviation at 1.023 .

Table 4.5 Attainment of education

\begin{tabular}{|c|c|c|c|c|c|c|c|}
\hline Attainment of education & $\begin{array}{l}\text { SA } \\
(\%)\end{array}$ & $\begin{array}{l}\text { A } \\
(\%)\end{array}$ & $\begin{array}{l}\mathbf{N} \\
(\%)\end{array}$ & $\begin{array}{l}\text { D } \\
(\%)\end{array}$ & $\begin{array}{l}\text { SD } \\
(\%)\end{array}$ & Mean & $\begin{array}{l}\text { Std. } \\
\text { Deviation }\end{array}$ \\
\hline I value khat as opposed to getting an education & 7.6 & 34.8 & 6.1 & 48.5 & 3.0 & 2.95 & 1.129 \\
\hline Khat affects my performance in school & 3.0 & 31.8 & 6.1 & 51.5 & 7.6 & 2.71 & 1.092 \\
\hline Khat has led to school drop outs & 3.0 & 75.8 & 1.5 & 15.2 & 4.5 & 3.58 & 0.946 \\
\hline $\begin{array}{l}\text { Participating in selling of Khat affects the attainment } \\
\text { of education }\end{array}$ & 1.5 & 80.3 & 3.0 & 9.1 & 6.1 & 3.62 & 0.907 \\
\hline
\end{tabular}

\section{Head teacher responses}

The study sought to seek the head teacher's responses on the effects of khat on attainment of primary education. The findings are presented in table 4.6. The findings indicate that $80.3 \%$ agreed that they regularly hold meetings with class 7 and 8 pupils to discuss their awareness on the impact of khat on their education, 94\% agreed that they are aware of pupils in class 7 and 8 who have dropped out of school in order to fully participate in khat selling, $94 \%$ agreed that they take follow up actions to bring school drop outs back to class , $65.2 \%$ agreed that parents support the school in ensuring that the pupils attend classes instead of going Khat market, $45.5 \%$ agreed that the current education policies are sufficient in addressing the issue of the involvement of minors in the khat trade, $84.8 \%$ agreed that khat selling has led to an increase of school drop-outs, $80.3 \%$ agreed that they have encountered challenges in regularity of attendance of class 7 and 8 pupils in relation to khat market. The overall aggregate mean score for this Head teacher responses was 3.986 and the standard deviation at 0.935 .

Table 4.6 Head teacher responses

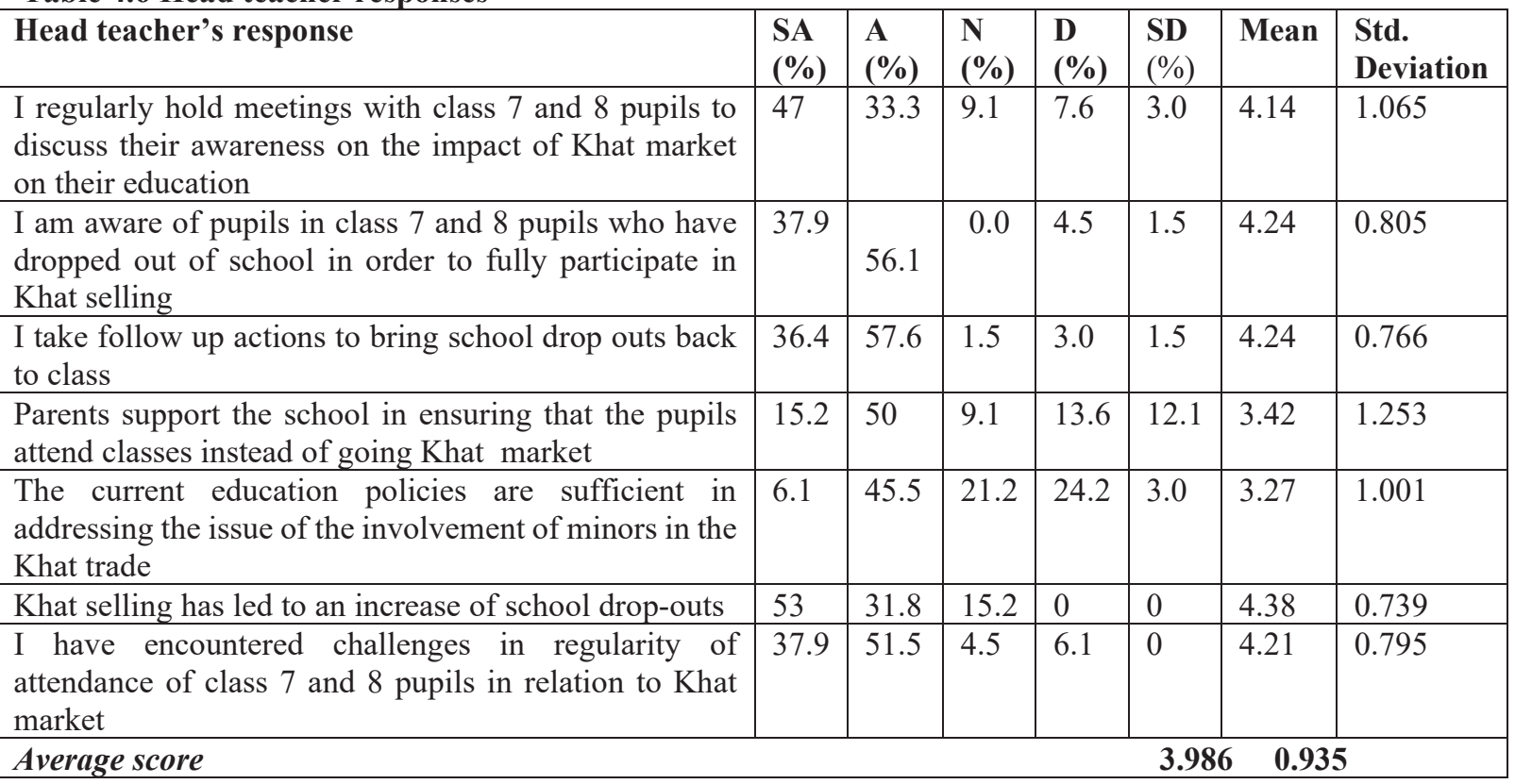


12. THE INFLUENCE OF THE KHAT MARKET ON ATTAINMENT OF PRIMARY EDUCATION

Pearson correlation coefficient was used to test the assumption of linearity between the dependent and the independent variables. Table 4.7 indicates that there was a significant negative linear relationship $(\mathrm{r}=-.108, \mathrm{p}<0.05)$ between khat selling and Attainment of education at 5\% level of significance. The results also indicate existence of a significant negative linear relationship $(\mathrm{r}=-0.057, \mathrm{p}<0.05)$ between awareness level and Attainment of education at $5 \%$ level of significance. Peer influence was found to have a significant negative linear relationship $(r=-0.237, p<0.05)$ with Attainment of education at $5 \%$ level of significance.

\section{Table 4.7 Linearity test}

Dependent variable

Attainment of the education

\begin{tabular}{lccll}
\hline Independent variables & Pearson Correlation & Sig. (2tailed) & $\mathrm{N}$ & Conclusion \\
\hline Khat selling & $-.108^{* *}$ & 0.000 & 66 & Linear \\
Awareness level & $-.057^{* *}$ & 0.000 & 66 & Linear \\
Peer influence & $-.237^{* *}$ & 0.000 & 66 & Linear \\
\hline
\end{tabular}

**. Correlation is significant at the 0.01 level (2-tailed).

\section{DISCUSSIONS}

This study examined the influence of khat market on attainment of primary education in Mogadishu, Somalia. The effects of khat were conceptualized to have three major determinants: khat selling, awareness level and peer influence. These three determinants were used to form the independent variables while attainment of primary education was the dependent variable.

The study found that there is a negative relationship between khat market and attainment of primary education. These findings reflect a similarity to the findings by Psucharopaulos (2009), in Venezuela and Bolivia conducted on children who were involved in child labour, against those who did not engage in it, indicated that, child labour leads to loss of two years schooling of the children. The loss of pupils schooling time consequently affected their educational performance.

\section{CONCLUSION}

The main purpose of this study was to determine the interrelationships among khat selling, awareness levels and peer influence on attainment of primary school education in Somalia. Data was collected using self-administered questionnaires that comprised of head teachers' and pupils questionnaire.

The study findings showed that khat traders preferred children labourers since they were paid cheaply and they were ready available. The money earned by children in khat trade was spent on luxuries. These children eventually drop out of school since they find no need of wasting time in school while they can make easy money from khat trade.

According to the findings of the study, peer influence is the most significant trigger of the learners to join khat market. Youngsters of the same age group tend to influence each other into doing things together. Majority of the pupils in Mogadishu indicated that they use drugs because their friends use. Peer influence prompts learners to engage in vices so as to fit in the peer groups.

\section{RECOMMENDATIONS}

The following recommendations were made based on the literature review and the empirical investigations in the study:

$>$ The Ministry of Education, Culture and Higher Education in conjunction with the Ministry of Woman and Human Rights Development should recognize and enforce the right of the child to be protected from economic exploitation at the family level and from performing any work that is likely to be hazardous or to interfere with the child's education.

$>$ The government should institute mechanisms that control khat consumption and selling within the community through the establishment of Cooperative Societies.

> The Ministry of Education, Culture and Higher Education in conjunction with the school heads should provide special remedial and weekend programmes for school going children. These programmes should incorporate discussions on the impact of khat market on education.

$>$ The Ministry of Health and Ministry of Education, Culture and Higher Education should start rehabilitation programmes for pupils who have already been adversely affected by the effects of khat consumption and selling. These programmes should incorporate back to school policies to enable dropouts to be absorbed back into the education system without stigmatization. 


\section{References}

Awale, S., \& Sheikh Ali, A. (2018). Social and Economic Difficulties Caused by Khat Usage in Somalia. International Journal of Humanities and Social Science, 8(8).

Armstrong, E. (2008). Research note, crime, chemicals and culture: On the complexity of khat. Journal of Drugs Issues, 38(2), 631-648.

Anderson, D., Hailu, D., \& Klein, A. (2007). The khat controversy: Stimulating the debate on drugs. Berg Oxford.

Arteaga-Vallejo, J. (2016). Land, Child Labor, and Schooling: Longitudinal Evidence from Colombia and Mexico. Bass, L. E. (2004). Child labor in Sub-Saharan Africa, Boulder: Lynne Rienner. African Studies Review, 48(3), 161-162.

Ageely, H. M. (2009). Prevalence of Khat chewing in college and secondary (high) school students of Jazan region, Saudi Arabia. Harm Reduction Journal, 6(1), 11.

Bade, Z., Muturi, W., \& Samantar, M. (2017). Factors influencing khat consumption among youth in Garowe District, Puntland, Somalia. International Journal of Contemporary Applied Researches, 4(11), PP.1-22.

Basu, A. K., \& Chau, N. H. (2003). Targeting child labor in debt bondage: Evidence, theory, and policy implications. The World Bank Economic Review, 17(2), 255-281.

Basu, A. K., \& Chau, N. H. (2004). Exploitation of child labor and the dynamics of debt bondage. Journal of Economic Growth, 9(2), 209-238.

Basu, K., \& Van, P. H. (1999). The economics of child labor: Reply. American Economic Review, 89(5), 13861388.

Basu, K., Das, S., \& Dutta, B. (2010). Child labor and household wealth: Theory and empirical evidence of an inverted-U. Journal of development economics, 91(1), 8-14.

Becker, S. O., Hornung, E., \& Woessmann, L. (2011). Education and catch-up in the industrial revolution. American Economic Journal: Macroeconomics, 3(3), 92-126.

Beckerleg, S. (2008). Khat special edition introduction. Substance Use \& Misuse, 43(6), 749-761.

Carrier, N. (2008). Is miraa a drug?: Categorizing Kenyan khat. Substance Use \& Misuse, 43(6), 803-818.

Dessy, S. E., Mbiekop, F., \& Pallage, S. (2005). The economics of child trafficking (part II). Cahier de recherche/Working Paper, 5, 09.

Dumas, C. (2007). Why do parents make their children work? A test of the poverty hypothesis in rural areas of Burkina Faso. Oxford Economic Papers, 59(2), 301-329.

Elmi, A. S. (1983). The chewing of khat in Somalia. Journal of Ethno pharmacology, 8(2), 163-176.

Fitzgerald, J. (2009). Khat: a literature review. Centre for culture, ethnicity \& health.

Gebissa, E. (2008). Scourge of life or an economic lifeline? Public discourses on khat (catha edulis) in Ethiopia. Substance Use \& Misuse, 43(6), 784-802.

Grootaert, C., \& Kanbur, R. (1995). Child labour: an economic perspective. Int'l Lab. Rev., 134, 187.

Hassan, N. A. G. M., Gunaid, A. A., \& Murray Lyon, I. M. (2007). Khat [Catha edulis]: health aspects of khat chewing.

Herath, G., \& Sharma, K. (2007). Labour and Economic Development: emerging issues in developing Asia. Child Labour in South Asia, 1.

Hilgert, M. A., Hogarth, J. M., \& Beverly, S. G. (2003). Household financial management: The connection between knowledge and behavior. Fed. Res. Bull., 89, 309.

Houghton, P. (2005). UK miraa ban to cost Kenya \$250m a year. Asian Journal of Business and Management Sciences. Retrieved from http://www.somalilandtimes.net/sl/2005/205/24.shtml Israel, G. D. (1992). Determining sample size.

Jalilian, H., \& Kirkpatrick, C. (2002). Financial development and poverty reduction in developing countries. International journal of finance \& economics, 7(2), 97-108.

Khanam, R. (2008). Child labour and school attendance: evidence from Bangladesh. International Journal of Social Economics, 35(1/2), 77-98.

Kothari, C. R. (2004). Research methodology: Methods and techniques. New Age International.

Longnecker, M. (2001). An introduction to statistical methods and data analysis (5th ed.).

Florence.

Maingi, P. K. (2013). Effects of Miraa Trade On Regularity of Attendance Of Primary School Pupils In Meru County-Kenya

Mohamed, J., \& Ibrahim, Y. (2012). Diverse effects of Khat on Somali families. International Social Work \& Social Problems.

Mwenda, J. M., Arimi, M. M., Kyama, M. C., \& Langat, D. K. (2003). Effects of khat (Catha edulis) consumption on reproductive functions: a review. East African Medical Journal, 80(6), 318-323.

Njeru, A. S. K. (2018). The effect of khat economy on attainment of primary education in Embu County, Kenya.

Nabuzoka, D., \& Badhadhe, F. A. (2000). Use and perceptions of khat among young Somalis in a UK city. Addiction Research, 8(1), 5-26. 
Njeru, L. K. (2013). Influence of Khat (Miraa) Production, Trade and Consumption on Primary School Dropout among the Boys in Kangeta Division, Igembe South District, Kenya.

Odenwald, M. (2007). Chronic khat use and psychotic disorders: a review of the literature and future prospects. Sucht, 53(1), 9-22

Pantelis, C., Hindler, C. G., \& Taylor, J. C. (1989). Use and abuse of khat (Catha edulis): a review of the distribution, pharmacology, side effects and a description of psychosis attributed to khat chewing. Psychological medicine, 19(3), 657-668.

Patel, N. B. (2000). Mechanism of action of cathinone: the active ingredient of Khat (Catha Edulis. East African Medical Journal, 77(6).

Patel, S. L. (2008). Attitudes to khat use within the Somali community in England. Drugs: education, prevention and policy, 15(1), 37-53.

Patel, S. L., Murray, R., \& Britain, G. (2005). Khat use among Somalis in four English cities. London: Home office.

Patel, S. L., Wright, S., \& Gammampila, A. (2005). Khat use among Somalis in four English cities. PsycEXTRA Dataset.

Psacharopoulos, G. (1997). Child labor versus educational attainment Some evidence from Latin America. Journal of population economics, 10(4), 377-386.

Rogers, C. A., \& Swinnerton, K. A. (2008). A theory of exploitative child labor. Oxford Economic Papers, 60(1), $20-41$.

Sikiru, L., \& Babu, S. (2009). Khat (Catha edulis): academic, health and psychosocial effects on "mature" students. African Journal of Drug and Alcohol Studies, 8(2).

Skinner, B. F. (1953). Science and human behavior (No. 92904). Simon and Schuster.

Soenens, B., \& Vansteenkiste, M. (2005). Antecedents and outcomes of self-determination in 3 life domains: The role of parents' and teachers' autonomy support. Journal of Youth and Adolescence, 34(6), 589-604.

Stevenson, M., Fitzgerald, J., \& Banwell, C. (1996). Chewing as a social act: cultural displacement and khat consumption in the East African communities of Melbourne. Drug and Alcohol Review, 15(1), 73-82.

Swinnerton, K. A. (1997). An essay on economic efficiency and core labour standards. World Economy, 20(1), 73-86.

UNICEF. (2017).Somalia Education Cluster Annual report 2016. 